\title{
Atividades Extraclasses com base no Currículo Mínimo para a Língua Inglesa usando uma Rede Social
}

\author{
Cristina de Almeida Rodrigues ${ }^{1}$, Marcos da Fonseca Elia ${ }^{2}$ \\ ${ }^{1,2}$ Programa de Pós Graduação em Informática (PPGI) - Universidade Federal do Rio de \\ Janeiro (UFRJ) \\ crisnewenglish@hotmail.com, melia@nce.ufrj.br
}

\begin{abstract}
Teenagers are called digital natives, because they grew and played with digital technology. It is necessary to use technological tools to attract the attention of these young people with regard to education. This paper seeks to show that it is possible to use ICT and social networks in improving student learning. Besides Facebook to be a social network, it can also be the basis for an architecture that will help teachers Foreign Language to awaken the interest of the students, encouraging them in the activities done in the classroom as at home, and apply the Matrix Reference of Minimum Curriculum Foreign Language.
\end{abstract}

Resumo: Os adolescentes são chamados nativos digitais, pois cresceram e brincaram com a tecnologia digital. Faz-se necessário o uso de ferramentas tecnológicas para atrair a atenção desses jovens no que diz respeito à educação. O presente trabalho procura mostrar que é possível utilizar as TIC e as redes sociais na melhoria da aprendizagem do aluno. Além de o Facebook ser uma rede social, ele também pode ser a base de uma Arquitetura Pedagógica que ajudará os professores de Língua Estrangeira a despertarem o interesse dos alunos; estimulando-os tanto nas atividades feitas em sala de aula quanto extraclasses; e aplicarem a Matriz de Referência do Currículo Mínimo da Língua Estrangeira.

\section{Introdução}

A motivação inicial desta pesquisa nasceu da experiência profissional do primeiro autor deste artigo como professor de Língua Inglesa do Ensino Médio e Fundamental. Durante os 18 anos que lecionou, encontrou dificuldades em motivar os alunos a participarem das aulas. Durante alguns anos, criava atividades que considerava interessantes por não estarem tão ligadas ao livro didático, como música, palavras cruzadas, e pesquisa sobre temas pontuais (Copa do Mundo, Olimpíadas, etc).

Nos anos de 2010 e 2011 trabalhou com as turmas utilizando o Yahoo Groups e a rede social Orkut, a partir de 2012 a pedido dos próprios alunos começou a utilizar o Facebook. Em princípio, a motivação era aumentar a participação e o interesse dos alunos. $\mathrm{Na}$ medida em que a participação e o interesse aumentaram, decidiu avaliar o Facebook como uma possível ferramenta para uso dos professores nas aulas de língua estrangeira.

Hoje os imigrantes digitais (professores) educam os nativos digitais (alunos). De acordo com Prensky (2011), "os nativos digitais são aqueles que cresceram cercados por tecnologias digitais. Para eles, a tecnologia analógica do século 20 - como câmeras de vídeo, telefones com fio, informação não conectada (livros, por exemplo), internet discada - é velha. Os nativos digitais cresceram com a tecnologia digital e usaram isso brincando, 
por isso não têm medo dela, veem-na como um aliado. Já os imigrantes digitais são os que chegaram à tecnologia digital mais tarde na vida e, por isso, precisaram se adaptar." Assim o professor necessita se atualizar para conseguir acompanhar os seus alunos.

Segundo os Parâmetros Curriculares Nacionais (PCN), o uso das tecnologias é recomendado como aliado do professor nas práticas pedagógicas: "É indiscutível a necessidade crescente do uso de computadores pelos alunos como instrumento de aprendizagem escolar, para que possam estar atualizados em relação às novas tecnologias da informação e se instrumentalizarem para as demandas sociais presentes e futuras." [Brasil, 1998, p. 96]

Através do uso das Tecnologias da Informação e da Comunicação (TIC), o docente pode compartilhar informações/conteúdos, passar atividade extraclasse (que em sala de aula, talvez os alunos tivessem dificuldades em realizá-la), como a criação de um vídeo, utilização de um tradutor on-line, participação dos alunos e professor em um chat, etc. A inclusão das TIC no âmbito escolar, sendo através do uso do computador, do celular ou do tablet, pode auxiliar o professor em suas atividades.

Além de motivar o interesse do aluno para o conteúdo escolar, o professor deve desenvolver atividades que façam parte do Currículo Mínimo (CM) que foi implantado na Rede Estadual do Rio de Janeiro pela Secretaria Estadual de Educação (SEEDUC) em 2011. [SEEDUC, 2011] Sua finalidade é que o aluno tenha o mínimo de competência e habilidade durante cada bimestre ao longo do ano letivo; assim se o aluno for transferido de colégio, o conteúdo mínimo será o mesmo. Além das competências e habilidades, o CM também propõe atividades para serem feitas com os alunos em sala de aula ou como atividade extraclasse. Ele surgiu como uma medida de governo para ser tornar uma política de Estado e seu uso é obrigatório por todos os professores da rede.

O CM não foi bem recebido pelos docentes, e a resistência por parte deles ainda existe. O seu conteúdo deve ser registrado no diário escolar e ser confirmado no site Conexão Educação - Docente Online que é um portal da Entretanto lançar o conteúdo no diário ou no site, não quer dizer que estejam sendo ministrados aos alunos. Por enquanto, saber se eles estão de fato cumprindo o $\mathrm{CM}$, é algo que não pode ser comprovado. Conforme Quirino (2011), "O currículo até pode vir moldado por instituições públicas, no entanto, o resultado final idealizado, não é passível de ser totalmente atingido. Isto porque professor e aluno possuem seus próprios meios de recepção (contexto cultural) daquilo que está sendo transmitido e recebido".

Atualmente as redes sociais estão sendo vistas como uma nova ferramenta para ajudar os professores em suas práticas. Para Lorenzo (2011), "As redes sociais também podem ser usadas de inúmeras maneiras pelos educadores, tais como: criar comunidades de aprendizagem para a escola, classe ou disciplina; compartilhar metodologia, programas, informações e ideias com outros professores; gerar um relacionamento didático e dinâmico entre profissionais da área etc.”.

Acreditamos que as redes sociais, possam vir a ser a conexão entre a realização das atividades que compõem as competências e habilidades da Língua Inglesa às práticas pedagógicas dos professores desta disciplina. Como a maioria dos alunos acessa a Internet, em especial, as redes sociais, de qualquer lugar e a qualquer momento constantemente, o professor pode usar este recurso para expandir as suas aulas para além da sala de aula, sem aumentar a sua carga horária, encontrando assim um ambiente onde possa aumentar o 
número de tarefas, que correspondam ao $\mathrm{CM}$, que não seriam possíveis de serem completadas dentro do horário escolar.

O Facebook (FB) é um exemplo de uma rede social que pode ser utilizada em parceria com a educação escolar. O seu manejo é fácil, o nível de interação entre os participantes pode ser alto, e a idade mínima legal de um participante é 13 anos, não sendo, portanto, um problema para os alunos do Ensino Médio (EM) utilizá-lo. Os alunos acessam essa rede com muita frequência, o que facilita a realização das atividades extraclasse da Língua Inglesa. Por este motivo, ele vem sendo avaliado como uma possível ferramenta para auxiliar o docente na sua prática e, no cumprimento do $\mathrm{CM}$ e na motivação do aluno quanto à aprendizagem do inglês.

Segundo Marcon (2012), acredita-se que a aprendizagem pode ser potencializada a partir do diálogo e do estabelecimento de relações com as novas tecnologias. Podemos considerar o Facebook, então, como um ambiente de aprendizagem.

Este artigo é composto por 4 seções. Após a Introdução, na seção 2, apresentamos a Arquitetura Pedagógica, na seção 3, Resultados Obtidos e na última, Considerações Finais.

\section{Arquitetura Pedagógica}

Este estudo surgiu de um experimento piloto que está calcado em atividades didáticas contextualizadas tendo como base a matriz de referência do Currículo Mínimo. Elas vêm sendo construídas ao longo destes 3 anos e já foram criadas mais ou menos 80 atividades. Muitas estão sendo adaptadas ao estilo do aluno. Alguns multimeios digitais estão sendo utilizados: vídeos postados no Youtube ou criados pelos alunos, tradutor de texto on-line, sites de pesquisas, dentre outros, para realizar as tarefas em sala de aula e extraclasses no Facebook.

Segundo Almeida (2003), ensinar em ambientes digitais e interativos de aprendizagem significa: organizar situações de aprendizagem, planejar e propor atividades; disponibilizar materiais de apoio com o uso de múltiplas mídias e linguagens; ter um professor que atue como mediador e orientador do aluno, procurando identificar suas representações de pensamento; fornecer informações relevantes, incentivar a busca de distintas fontes de informações e a realização de experimentações; provocar a reflexão sobre processos e produtos; favorecer a formalização de conceitos; propiciar a interaprendizagem e a aprendizagem significativa do aluno.

Pierre Lévy (2012) defende a ideia de que as redes sociais podem ser utilizadas no ensino presencial e na aprendizagem. Ele faz com que os seus alunos criem grupos no Facebook, postem textos ou vídeos e participem de grupos de discussão. "O Facebook é apenas uma das mídias sociais em um contexto de participação. Não são as novas mídias que terão impacto negativo. São as pessoas que postam coisas negativas. É como se perguntar qual o impacto negativo da linguagem porque tem muita mentira. Não é a linguagem que tem impacto negativo, são os mentirosos!”, comparou.

Inicialmente foram criados grupos restritos (um para cada turma) no Facebook para que os alunos participassem, seja desenvolvendo as atividades propostas pelo professor $(1: \mathrm{N})$, seja eles próprios propondo atividades ou ajudando os colegas a resolverem as atividades em andamento (N:N) são exemplos de algumas inovações feitas. 
$\mathrm{O}$ estudo começou com os alunos dos $2^{\circ}$ e $3^{\circ}$ anos do Ensino Médio do Colégio Estadual Liceu Nilo Peçanha em Niterói, Rio de Janeiro em 2012, 149 alunos no total. Foram 4 turmas de $2^{\circ}$ ano (97 alunos) e 2 turmas do $3^{\circ}$ ano (52 alunos) com atividades iguais entre as turmas do mesmo ano. Em 2013, o estudo está sendo realizado com 6 turmas, uma turma do $1^{\circ}$ ano ( 35 alunos), 3 turmas do $2^{\circ}$ ano (94 alunos) e duas turmas do $3^{\circ}$ ano (42 alunos), 171 alunos no total.

Algumas alterações foram feitas a partir do estudo inicial. Em todas as atividades postadas no Facebook, os alunos fazem a tarefa, postam e precisam comentar a postagem de outro aluno. O questionário de estilos de aprendizagem foi enviado ao aluno no início do ano letivo de 2013. Com isso, o professor deixou de ser rígido quanto ao cumprimento das tarefas. Os alunos que não têm acesso à Internet, podem realizar as atividades de outra forma, digitando, desenhando, pesquisando em livros, etc. As avaliações passaram a conter questões relativas ao $\mathrm{CM}$; antes ficavam restritas ao FB.

O livro didático utilizado é o Upgrade Volume 1, 2 e 3. A partir do conteúdo do livro e do currículo mínimo, os alunos fizeram e fazem as atividades e trabalhos.

Ao longo de cada bimestre, foram postadas 4 atividades estruturadas no Facebook, a partir da Matriz de Referência do Currículo Mínimo. Cada atividade vale 0,5 ponto. Os alunos postam o que o professor pede, fazem um comentário na postagem de um colega, ambas escritas em Inglês. Depois aguardam a correção. Se tiverem a postagem "curtida" tanto na sua quanto no comentário feito a outro aluno, a tarefa foi válida. Se algo estiver errado, será enviado uma mensagem para esse aluno corrigir o que não estiver conforme foi pedido. Os alunos fizeram exercícios e/ou trabalhos, dos conteúdos dados em sala de aula.

As questões das provas e testes fizeram parte do conteúdo bimestral e do CM. O valor do teste foi 2,0 pontos e da prova, 4,0 pontos. Os alunos também foram avaliados durante as aulas nos seguintes quesitos: participação nas aulas; realização dos exercícios de aula e casa; frequência; atividades no Facebook realizadas e comportamento. A participação valeu 2,0 pontos por bimestre. $O$ aluno que não consegue ter média igual a 5,0 terá uma nova chance através da recuperação paralela. $\mathrm{O}$ aluno faz uma avaliação de recuperação valendo 6,0. Assim ninguém ficará prejudicado.

No fim do ano de 2012 e no início do primeiro bimestre de 2013 foi aplicado o questionário Estilo de Aprendizagem (ILS - Index of Learning Styles), criado por Felder, com o objetivo de verificar se as atividades feitas no FB dependiam do estilo de aprendizagem dos alunos. Ele tem 4 escalas bipolares: Ativo-Reflexivo; SensorialIntuitivo; Visual-Verbal e Sequencial-Global. Possuindo os seguintes resultados:11 (Extremamente): preferência muito forte. Terá muita dificuldade para aprender em situações que não o favorecerem; 9 (Muito): preferência forte. Terá dificuldades para aprender em situações que não o favorecerem; 5 (Moderado): preferência fraca. Aprenderá com facilidades em situações que o favorecerem; 1 (Equilibrado): nenhuma preferência. Bem balanceado. 


\section{Resultados Obtidos}

\section{Criação de grupos no FB}

Os grupos foram criados para que os alunos pudessem criar as tarefas. Sem os grupos ficaria impossível fazer o trabalho desejado. Pois as atividades se misturariam as demais postagens que não teriam a mesma finalidade. Os alunos foram participativos no grupo e tiveram um ótimo relacionamento entre eles. No ano de 2012, em duas turmas do $3^{\circ}$ ano, o professor de Filosofia também pediu para usar o grupo para postar vídeos ou textos que usaria em sala de aula. Na turma do $2^{\circ}$ ano, a professora de História também passava atividades no grupo do FB.

\section{Atividades didáticas}

No quadro 1 são apresentadas algumas das 80 atividades didáticas desenvolvidas ao longo deste estudo no ano de 2012 e 2013, seguindo as orientações gerais dicutidas na seção 2 , tendo como Fonte ( $3^{\mathrm{a}}$ coluna) e a respectiva matriz de referência do $\mathrm{CM}$ ou o livro didático (LD). Na $1^{\text {a }}$ coluna são dadas uma breve descrição, na $2^{\mathrm{a}}$ coluna, cada Competência e Habilidade são identificadas pelo código criado ( $2^{\mathrm{a}}$ coluna) caso a fonte seja o CM, na $4^{\mathrm{a}}$ coluna e $5^{a}$ coluna são apresentados respectivamente o estilo de aprendizagem em que a atividade foi categorizada e o período letivo em que foi aplicado.

Essas atividades constituem um banco de atividades que será colocado disponível para outros professores da língua inglesa que queiram também utilizar o FB em sua prática docente. Um dos seus usos possíveis é avaliar o desemepenho em uma dada competência/ habilidade combinando os escores alcançados pelos alunos nas atividades que versam sobre a competência/ habilidade de interesse.

Quadro 1. Atividades didáticas realizadas em 2012 nas turmas de $2^{\circ}$ e $3^{\circ}$ ano do ensino médio

\begin{tabular}{|c|c|c|c|c|}
\hline Descrição & Código MR & Fonte & Estilo & Per Apl \\
\hline 1 - Faça, em inglês, a sinopse de um filme. & - & LD & Verbal & $1^{\circ} \mathrm{bim}$ \\
\hline 2 - Escolha um filme e explicar porque gostou. & - & LD & Verbal & $1^{\circ} \mathrm{bim}$ \\
\hline $\begin{array}{l}3 \text { - Escreva algo sobre você. Usem o Present } \\
\text { Perfect. }\end{array}$ & C2H2B1 & $\mathrm{CM}$ & Verbal & $1^{\circ} \mathrm{bim}$ \\
\hline 12 - Faça um Currículo Vitae. & $\begin{array}{l}\text { C1H1B1 } \\
\text { C1H2B1 } \\
\text { C1H3B1 }\end{array}$ & $\begin{array}{l}\mathrm{CM} \\
\mathrm{CM} \\
\mathrm{CM} \\
\end{array}$ & Verbal & $1^{\circ}$ bim \\
\hline 13 - Faça um pequeno texto de apresentação. & C1H3B1 & $\mathrm{CM}$ & $\begin{array}{l}\text { Verbal } \\
\text { Reflexivo }\end{array}$ & $1^{\circ}$ bim \\
\hline $\begin{array}{l}14 \text { - Escolha uma história em quadrinhos em } \\
\text { inglês. }\end{array}$ & $\begin{array}{l}\text { C2H1B3 } \\
\text { C2H2B3 }\end{array}$ & $\mathrm{CM}$ & Visual & $1^{\circ}$ bim \\
\hline$\square$ & & & & \\
\hline $\begin{array}{l}41 \text { - Dê a sua opinião (em inglês) sobre a Lei } \\
\text { Federal } n^{\circ} 8213 \text {, de } 24 \text { de julho de 1991, } \\
\text { regulamentada pelo Decreto Federal 3.298, de } 20 \\
\text { de dezembro de } 1999 \text {. }\end{array}$ & - & LD & Verbal & $4^{\mathrm{o}} \mathrm{bim}$ \\
\hline
\end{tabular}




\begin{tabular}{|l|l|l|l|l|}
\hline 42 - As cantinas nos colégios do Estado do RJ & - & LD & Verbal & $4^{\circ}$ bim \\
foram fechadas por alguns motivos, inclusive a \\
obesidade entre os adolescentes. Como ela \\
poderia ser evitada dentro de um colégio? Um \\
adolescente pode fazer a operação para reduzir o \\
estômago? Quais são os tipos de redução que \\
existem e quais os prós e os contras? (Responda \\
em inglês.)
\end{tabular}

\section{Análise dos Estilos de Aprendizagem vs. Desempenho Atividade no FB}

O objetivo desta análise é verificar se o desempenho dos alunos nas atividades feitas no Facebook depende do estilo de aprendizagem. As tabelas 1-4 mostram separadamente para cada ano $(2012,2013)$ e bimestre letivo $\left(1^{\circ}\right.$ a $\left.4^{\circ}\right)$ a diferença das médias de desempenho $(\%)$ entre os alunos classificados nos diferentes polos $(-$ ou +$)$ repectivamente para cada uma das 4 escalas LSF [Felder,1988].

Analisando estas tabelas para 2012 verificamos que ao longo dos 4 bimestres, embora a diferença não seja significativa em todos os casos, o desempenho é sempre maior para aqueles alunos que têm um estilo de aprendizagem "Ativo AR + Intuitivo SI + Visual VV + Global SG”. Esse padrão não é observado em 2013 e as diferenças em geral tornaram-se menos significativas ao longo dos 2 bimestres iniciais, exceto para o estilo Visual-Verbal no $2^{\circ}$.bimestre (Tabela 3). Uma explicação plausível é que este resultado já esteja refletindo as mudanças introduzidas em 2013, a partir da constatação do resultado de 2012, em que uma das quais consistiu em aplicar atividades no FB adaptadas ao estilo de aprendizagem do aluno.

Tabela 1 - Estilo: Ativo (+) - Equilibrado (0) - Reflexivo (-) - $N_{0} I N_{1}=76$ I 19

\begin{tabular}{|c|c|c|c|c|}
\hline \multirow{2}{*}{$\begin{array}{c}\text { Facebook } \\
\text { Bimestres }\end{array}$} & \multicolumn{2}{|c|}{2012} & \multicolumn{2}{c|}{2013} \\
\cline { 2 - 5 } & $\mathrm{M}_{-}-\mathrm{M}_{+}(\%)$ & Sig (\%) & $\mathrm{M}_{-}-\mathrm{M}_{+}(\%)$ & Sig (\%) \\
\hline $1^{\mathbf{o}}$ & $44-66$ & 7 & $62-65$ & 82 \\
\hline $2^{\mathbf{o}}$ & $38-53$ & 8 & $62-75$ & 19 \\
\hline $3^{\text {o }}$ & $45-71$ & 0 & - & - \\
\hline $4^{\mathbf{0}}$ & $59-83$ & 1 & - & - \\
\hline
\end{tabular}

Tabela 2 - Estilo: Sensorial (+) - Intuitivo (-) - $N_{-1} I N_{1}=4$ I 19

\begin{tabular}{|c|c|c|c|c|}
\hline \multirow{2}{*}{$\begin{array}{c}\text { Facebook } \\
\text { Bimestres }\end{array}$} & \multicolumn{2}{|c|}{2012} & \multicolumn{2}{c|}{2013} \\
\cline { 2 - 5 } & $\mathrm{M}_{-}-\mathrm{M}_{+}(\%)$ & Sig (\%) & $\mathrm{M}_{-}-\mathrm{M}_{+}(\%)$ & Sig (\%) \\
\hline $1^{\mathbf{o}}$ & $75-61$ & 63 & $46-56$ & 60 \\
\hline $2^{\mathbf{o}}$ & $75-32$ & 5 & $40-72$ & 17 \\
\hline $3^{\mathrm{o}}$ & $75-61$ & 41 & - & - \\
\hline $4^{\mathbf{o}}$ & $68-68$ & 72 & - & - \\
\hline
\end{tabular}

Tabela 3 - Estilo: Visual (+) - Verbal (-) - $\mathrm{N}_{-1}$ I $N_{1}=6$ I 14

\begin{tabular}{|c|c|c|c|c|}
\hline \multirow{2}{*}{$\begin{array}{c}\text { Facebook } \\
\text { Bimestres }\end{array}$} & \multicolumn{2}{|c|}{2012} & \multicolumn{2}{c|}{2013} \\
\cline { 2 - 5 } & $\mathrm{M}_{-}-\mathrm{M}_{+}(\%)$ & $\mathrm{Sig}(\%)$ & $\mathrm{M}_{-}-\mathrm{M}_{+}(\%)$ & Sig (\%) \\
\hline $1^{\mathbf{0}}$ & $50-75$ & 34 & $65-49$ & 24 \\
\hline $2^{\mathbf{o}}$ & $33-50$ & 21 & $83-58$ & 1 \\
\hline $3^{\mathbf{o}}$ & $42-61$ & 15 & - & - \\
\hline $4^{\mathbf{o}}$ & $25-88$ & 1 & - & - \\
\hline
\end{tabular}


Tabela 4 - Estilo: Sequencial (1) - Global (-1) - $N_{-1}$ I $N_{1}=5$ I 12

\begin{tabular}{|c|c|c|c|c|}
\hline \multirow{2}{*}{$\begin{array}{c}\text { Facebook } \\
\text { Bimestres }\end{array}$} & \multicolumn{2}{|c|}{2012} & \multicolumn{2}{c|}{2013} \\
\cline { 2 - 5 } & $\mathrm{M}_{-}-\mathrm{M}_{+}(\%)$ & Sig (\%) & $\mathrm{M}_{-}-\mathrm{M}_{+}(\%)$ & Sig (\%) \\
\hline $1^{\mathbf{o}}$ & $70-50$ & 7 & $54-59$ & 77 \\
\hline $2^{\text {o }}$ & $40-33$ & 8 & $43-49$ & 72 \\
\hline $3^{\mathrm{o}}$ & $60-46$ & 0 & - & - \\
\hline $4^{\mathbf{o}}$ & $80-68$ & 1 & - & - \\
\hline
\end{tabular}

Análise dos Resultados da Avaliação por Séries, por Bimestres e por Instrumentos em 2012 e até o $2^{\circ}$ bimestre de 2013

As Tabelas 5 a 9 mostram, separadamente para cada série $\left(1^{\mathrm{a}}, 2^{\mathrm{a}}\right.$ e $\left.3^{\mathrm{a}}\right)$ e para os anos de análise $(2012,2013)$ os dados referentes à média do bimestre ( $2^{\mathrm{a}}$ e $3^{\mathrm{a}}$ colunas) respectivamente para cada um dos 4 bimestres. As demais colunas à direita mostram o rank do valor de alfa de cada um dos 4 instrumentos (Facebook, prova, participação e atividades) quando cada instrumento é retirado um por vez da análise.

Tabela 5: Como se pode notar as médias ficaram em torno de $50 \%$, com exceção do $3^{\circ}$ bimestre atipicamente mais baixo (43\%). Da mesma forma, os valores de alfa refletem uma consistência razoável entre $50 \%$ e $60 \%$, com exceção novamente do $3^{\circ}$ bimestre $(18 \%)$. Ou seja, tanto em termo de nível como em estrutura, os dados apresentam atipicidade no $3^{\circ}$ bimestre. Neste caso, poucos alunos completaram corretamente as atividades, levando a alteração no alfa de Cronbach. E, quando inspecionando os dados referentes à ordem dos instrumentos, verifica-se que, em média, o Facebook ocupa a pior posição e que a prova ocupa a melhor. Novamente há uma atipicidade no $3^{\circ}$ bimestre em relação ao Facebook.

Tabela 5 - Análise das médias e da consistência - 2º ano (2012)

\begin{tabular}{|c|c|c|c|c|c|c|}
\hline $\begin{array}{c}\text { Bimestre } \\
\mathbf{2 0 1 2}\end{array}$ & $\begin{array}{c}\text { Média Bim \% } \\
\text { (Nal) }\end{array}$ & $\begin{array}{c}\text { Alfa } \\
\text { (4 Itens) }\end{array}$ & \multicolumn{5}{|c|}{ Rank do alfa se instrumento for retirado da escala } \\
\hline & & & Fbook & Prova & Participação & Atividade \\
\hline $\mathbf{1}^{\mathbf{o}}$ & $56 \%(95)$ & 0,61 & $4^{\text {o }}$ & $3^{\text {o }}$ & $1^{\text {o }}$ & $2^{\text {o }}$ \\
\hline $\mathbf{2}^{\mathbf{o}}$ & $49 \%(96)$ & 0,57 & $4^{\text {o }}$ & $2^{\text {o }}$ & $3^{\text {o }}$ & $1^{\text {o }}$ \\
\hline $\mathbf{3}^{\mathbf{o}}$ & $42 \%(96)$ & 0,18 & $1^{\text {o }}$ & $2^{\text {o }}$ & $4^{\text {o }}$ & $3^{\text {o }}$ \\
\hline $\mathbf{4}^{\mathbf{o}}$ & $58 \%(93)$ & 0,53 & $4^{\text {o }}$ & $2^{\text {o }}$ & $1^{\text {o }}$ & $3^{\text {o }}$ \\
\hline Média & $51 \%$ & & $2^{\text {o }}$ & $1^{\text {o }}$ & $1^{\text {o }}$ & $1^{\text {o }}$ \\
\hline
\end{tabular}

Tabela 6 - Análise das médias e da consistência - 3ํano (2012)

\begin{tabular}{|c|c|c|c|c|c|c|}
\hline $\begin{array}{c}\text { Bimestre } \\
\mathbf{2 0 1 2}\end{array}$ & $\begin{array}{c}\text { Média Bim \% } \\
\text { (Nal) }\end{array}$ & $\begin{array}{c}\text { Alfa } \\
\text { (4 Itens) }\end{array}$ & \multicolumn{5}{|c|}{ Rank do alfa se instrumento for retirado da escala } \\
\hline & & & Fbook & Prova & Participação & Atividade \\
\hline $\mathbf{1}^{\mathbf{o}}$ & $80 \%(50)$ & 0,39 & $1^{\text {o }}$ & $4^{\text {o }}$ & $3^{\text {o }}$ & $2^{\text {o }}$ \\
\hline $\mathbf{2}^{\mathbf{o}}$ & $60 \%(51)$ & 0,70 & $4^{\text {o }}$ & $2^{\text {o }}$ & $3^{\text {o }}$ & $1^{\text {o }}$ \\
\hline $3^{\text {o }}$ & $62 \%(52)$ & 0,30 & $1^{\text {o }}$ & $3^{\text {o }}$ & $2^{\text {o }}$ & $4^{\text {o }}$ \\
\hline $4^{\mathbf{o}}$ & $70 \%(52)$ & 0,35 & $1^{\text {o }}$ & $2^{\text {o }}$ & $3^{\text {o }}$ & $4^{\text {o }}$ \\
\hline Média & $68 \%$ & & $1^{\text {o }}$ & $2^{\text {o }}$ & $2^{\text {o }}$ & $2^{\text {o }}$ \\
\hline
\end{tabular}


Tabela 6: Os instrumentos apresentam uma consistência interna ruim medida pelo alfa de Cronbach padronizado, mas apresentam um valor atipicamente alto no $2^{\circ}$ bimestre, apesar das atividades feitas no Facebook terem ficado em último lugar no rank. Nos demais bimestres, estas atividades ficaram em $1^{\circ}$ lugar, talvez, porque quase todos os alunos estudaram com a autora do estudo nas duas primeiras séries, e já estavam acostumados com tarefas de inglês no Orkut $\left(1^{\circ}\right.$ ano) e Facebook $\left(2^{\circ}\right.$ ano). As médias no $1^{\circ}$ e $4^{\circ}$ bimestres ficaram bem acima dos $50 \%$, sendo que no $1^{\circ}$, quase atingiu $90 \%$; nos $2^{\circ}$ e $3^{\circ}$ bimestres também se mantiveram acima dos $50 \%$. No $1^{\circ}$ bimestre, a atividade no Facebook foi mais consistente do que a prova; No $2^{\circ}$ bimestre, a prova foi mais consistente, pois muitos alunos não fizeram todas as atividades no Facebook. Nos $3^{\circ}$ e $4^{\circ}$ bimestres, o Facebook voltou a ser mais consistente do que a prova.

Tabela 7 - Análise das médias e da consistência - 1ํo ano (2013)

\begin{tabular}{|c|c|c|c|c|c|c|}
\hline $\begin{array}{c}\text { Bimestre } \\
\mathbf{2 0 1 3}\end{array}$ & $\begin{array}{c}\text { Média Bim \% } \\
\text { (Nal) }\end{array}$ & $\begin{array}{c}\text { Alfa } \\
\text { (4 Itens) }\end{array}$ & \multicolumn{5}{|c|}{ Rank do alfa se instrumento for retirado da escala } \\
\hline & & & Fbook & Prova & Participação & Atividade \\
\hline $\mathbf{1}^{\mathbf{o}}$ & $38 \%(15)$ & 0,73 & $4^{\mathbf{o}}$ & $3^{\text {o }}$ & $1^{\text {o }}$ & $2^{\text {o }}$ \\
\hline $\mathbf{2}^{\mathbf{o}}$ & $49 \%(33)$ & 0,84 & $2^{\text {o }}$ & $1^{\text {o }}$ & $3^{\text {o }}$ & $4^{\text {o }}$ \\
\hline Média & $44 \%$ & 0,79 & $2^{\text {o }}$ & $1^{\text {o }}$ & $1^{\text {o }}$ & $2^{\text {o }}$ \\
\hline
\end{tabular}

Tabela 7: No $2^{\circ}$ estudo que está sendo realizado nas turmas do $1^{\circ}$ ano, pode-se notar que as médias ficaram em torno de $40 \%$. Da mesma forma, os valores de alfa refletem uma consistência de $79 \%$. No $1^{\circ}$ bimestre, somente 15 alunos participaram de todas as atividades, mas no $2^{\circ}$, houve um aumento de $100 \%$ de participação. Inspecionando os dados referentes à ordem dos instrumentos verificamos que o Facebook ocupa a pior posição no $1^{\circ}$ bimestre e a participação está na $1^{\mathrm{a}}$, há uma melhora no $2^{\circ}$ bimestre e ele passa a ocupar a $2^{\mathrm{a}}$ posição e a atividade (teste/trabalho) ocupa a pior.

Tabela 8 - Análise das médias e da consistência - 20 ano (2013)

\begin{tabular}{|c|c|c|c|c|c|c|}
\hline $\begin{array}{c}\text { Bimestre } \\
\mathbf{2 0 1 3}\end{array}$ & $\begin{array}{c}\text { Média Bim \% } \\
\text { (Nal) }\end{array}$ & $\begin{array}{c}\text { Alfa } \\
\text { (4 Itens) }\end{array}$ & \multicolumn{5}{|c|}{ Rank do alfa se instrumento for retirado da escala } \\
\hline & & & Fbook & Prova & Participação & Atividade \\
\hline $\mathbf{1}^{\mathbf{o}}$ & $54 \%(88)$ & 0,74 & $2^{\text {o }}$ & $1^{\text {o }}$ & $3^{\text {o }}$ & $4^{\text {o }}$ \\
\hline $\mathbf{2}^{\mathbf{o}}$ & $56 \%(95)$ & 0,83 & $2^{\text {o }}$ & $1^{\text {o }}$ & $3^{\text {o }}$ & $4^{\text {o }}$ \\
\hline Média & $55 \%$ & 0,79 & $2^{\text {o }}$ & $1^{\text {o }}$ & $3^{\text {o }}$ & $4^{\text {o }}$ \\
\hline
\end{tabular}

Tabela 8: Nas turmas do $2^{\circ}$ ano, nota-se que as médias ficaram em torno de $55 \%$. Da mesma forma, os valores de alfa refletem uma consistência de $79 \%$. No $1^{\circ}$ bimestre, 88 alunos participaram de todas as atividades, e houve um acréscimo ao número de participação. Verificando a ordem dos instrumentos no que se refere à consistência, o Facebook ocupa a segunda posição e a atividade (teste/trabalho) ocupa a pior. 
Tabela 9 - Análise das médias e da consistência - 3ำ ano (2013)

\begin{tabular}{|c|c|c|c|c|c|c|}
\hline $\begin{array}{c}\text { Bimestre } \\
2013\end{array}$ & $\begin{array}{c}\text { Média Bim \% } \\
\text { (Nal) }\end{array}$ & $\begin{array}{c}\text { Alfa } \\
\text { (4 Itens) }\end{array}$ & \multicolumn{5}{|c|}{ Rank do alfa se instrumento for retirado da escala } \\
\hline & & & Fbook & Prova & Participação & Atividade \\
\hline $\mathbf{1}^{\mathbf{o}}$ & $48 \%(43)$ & 0,74 & $4^{\text {o }}$ & $3^{\text {o }}$ & $1^{\text {o }}$ & $2^{\text {o }}$ \\
\hline $\mathbf{2}^{\mathbf{o}}$ & $76 \%(43)$ & 0,69 & $2^{\text {o }}$ & $1^{\text {o }}$ & $3^{\text {o }}$ & $4^{\text {o }}$ \\
\hline Média & $62 \%$ & 0,72 & $2^{\text {o }}$ & $1^{\text {o }}$ & $1^{\text {o }}$ & $2^{\text {o }}$ \\
\hline
\end{tabular}

Tabela 9: Finalizando, nas turmas do $3^{\circ}$ ano, as médias ficaram em torno de $62 \%$, sendo que no $1^{\circ}$ bimestre, a média ficou abaixo de $50 \%$. Da mesma forma, os valores de alfa refletem uma consistência de $72 \%$. O número de participação de alunos manteve-se a mesma nos dois bimestres. Verificando a ordem dos instrumentos no que se refere à consistência, o Facebook ocupa a segunda posição e a atividade (teste/trabalho) ocupa a pior.

Através dos estudos feitos e os que estão em andamento, pode-se notar que as atividades feitas no Facebook no $1^{\circ}$ bimestre tem pouca participação por parte dos alunos, mas ao longo dos bimestres, a participação melhora e os alunos sentem-se mais confortáveis em participar e tentar conversar em inglês no grupo ou em chat com o $1^{\circ}$ autor desse trabalho.

Nota-se também quando se inspeciona as $3^{\text {a }}$ colunas das tabelas 5 a 9 que houve uma melhora na consistência entre os 4 instrumentos utilizados quando se compara os estudos de 2012 e 2013. A explicação mais provável é que os alunos analisados em 2013 já estariam passando pelo processo pela segunda vez. De qualquer forma é um forte indício de que as atividades feitas no FB pouco a pouco vão se integrando às demais práticas escolares.

\section{Considerações Finais}

Os alunos se sentem à vontade em manusear esta rede social, além de fazerem parte do grupo criado pelo autor, também solicitam amizade virtual ao mesmo. Eles não se sentem invadidos pela presença dele em sua rede de amigos. Através do chat aproveitam para tirar dúvidas das atividades ou do conteúdo explicado em sala de aula.

Apesar das atividades terem se tornadas mais dinâmicas, alguns alunos reclamam, dizem que estão com preguiça e perguntam quantos pontos perderão se não as fizerem. Durante este ano, tiveram que gravar uma entrevista em inglês, utilizando o celular ou câmera digital, alguns alunos pediram para ficar nos "bastidores", pois tinham vergonha de serem gravados. Foi autorizado, mas a empolgação dos demais alunos foi contagiante. E somente uma aluna ficou no bastidor, ela filmou e editou a filmagem.

É um trabalho interessante, mas muito cansativo. Pois o número de alunos fica em torno de 100, e sendo multiplicado por 4, são 400 atividades que precisam ser corrigidas por bimestre. Então existe um grande aumento na carga horária desse professor que tenta ser inovador em sua disciplina, despertando no aluno um interesse que até então era inexistente.

Em relação a trabalhos futuros, também serão criados instrumentos para serem disponibilizados aos professores que desejarem aplicar a Matriz do CM utilizando uma rede social: 
a) uma aplicação (App) pedagógica no Facebook, onde serão colocadas todas as propostas de atividades elaboradas durante o ano pelos alunos. Ela ficará disponível para qualquer professor de língua estrangeira que desejar utilizá-la como modelo;

b) um repositório de atividades, tendo como referência a tabela de competências e habilidades do CM, em um banco de dados na WEB para que os professores possam acrescentar atividades relativas ao $\mathrm{CM}$ ou utilizar as que já estiverem no banco.

\section{Referências}

Almeida, Maria Elizabeth Bianconcini. Educação a distância na internet: abordagens e contribuições dos ambientes digitais de aprendizagem. Educação e Pesquisa, São Paulo, v.29, n.2, p. 327-340, jul./dez. 2003.

Brasil. MEC. 1998. Parâmetros Curriculares Nacionais. Brasília: MEC/SEF

Felder, R.M.; Silverman, Linda K.(1988). Learning and teaching styles in engineering education. Journal of Engineering Education, v. 78, n. 7, p. 674-681. Disponível em: http://www.ncsu.edu/felder-public/Learning_Styles.html Acesso em: 10 de novembro de 2012.

Lévy, Pierre. (2012) Entrevista dada ao site Agência Brasil - Empresa Brasil de Comunicação. Disponível em: http://agenciabrasil.ebc.com.br/noticia/2012-06-30/pierrelevy-preve-substituicao-do-livro-didatico-e-do-caderno-por-computadores-e-tablets-nassalas-de Acesso em 30 de maio de 2013.

Lorenzo, Eder Maia. (2011). A utilização das Redes Sociais na Educação. Disponível em http://followscience.com/content/469276/redes-sociais-na-educacao Acesso em 30 de maio de 2013.

Marcon, Karina; Machado, Juliana Brandão, Carvalho, Marie Jane Soares (2012). Arquiteturas Pedagógicas e Redes Sociais: Uma experiência no Facebook. Anais do $23^{\circ}$ Simpósio Brasileiro de Informática na Educação (SBIE 2012), ISSN 2316-6533 Rio de Janeiro.

Prensky, Marc (2011). From Digital Natives to Digital Wisdom. Published in From Digital Natives to Digital Wisdom: Hopeful Essays for 21st Century Education.

Quirino, Maria José da Silva de Oliveira; PEREIRA, Carlos Alexandre da Silva; LEAL, Cristianni Antunes; OLIVEIRA, Vânia Lucia.(2011) Políticas Curriculares: uma breve crítica ao Currículo Mínimo implantado no Estado do Rio de Janeiro.

SEEDUC. (2011). Currículo Mínimo. Disponível em: http://www.conexaoprofessor.rj.gov.br/curriculo aberto.asp Acesso em 02 de fevereiro de 2013. 